\title{
A Study of Problems Facing University Library Management and Service Innovation in the Information Age
}

\author{
Hui Wang ${ }^{1, *}$ \\ ${ }^{1}$ Library, University of Ji'nan, Ji'nan, Shandong 250022, China \\ *Corresponding author. Email: wanghuihui3603@126.com

\begin{abstract}
Nowadays, in China, the university library has become a standard configuration for every university and a venue for teachers and students to read and study. With the advent of the information age, network information technology grows rapidly, and some university libraries meet some management problems. For this, this article primarily explores the measures to solve these problems, and proposes a service innovation strategy for university libraries to further facilitate university library management.
\end{abstract}

Keywords: University library, Management work, Service improvement and service innovation.

\section{INTRODUCTION}

The information age brings library management work opportunities. In the traditional management model, the library assumes the responsibility of storing and transmitting information resources. While in the information age, the transmission of library information resources is accelerated, and new impetus is injected into the development model of the library industry. On the one hand, library information resources are converted into electronic information resources; on the other hand, libraries are able to use the Internet platform to carry out the library service model.

The Report of Development and Access to Information 2019[1] published by The International Federation of Library Associations and Institutions (IFLA) points out that the library has long been a core of human culture, as it not only keeps the memories of academic achievements but also is a source of innovation. Although there will be significant changes for libraries with the advent of the information age, yet in a manner of speaking the core mission of providing information resources is more important than ever. Against the backdrop of the data era revolution, existing services offered by libraries cannot meet information and data needs of users.[2]
Therefore, libraries need a transformation. During the period of transformation, data management and innovative service will become primary tasks for libraries.

\section{PROBLEMS EXISTING IN UNIVERSITY LIBRARY MANAGEMENT IN THE INFORMATION AGE}

\subsection{Some University Libraries Have Not Optimized the Allocation of Resources}

At present, the size of enrollment of universities is constantly growing every year, and the number of faculty and staff continues to increase. These two reasons require schools to invest more resources in libraries. However, some university libraries have a poor environment and a very limited number of books collected, unable to satisfy the needs of teachers and students for knowledge and learning environment. In addition, human needs for different types of information resources show the trend of diversification, which requires the library industry to achieve an informatized and intelligentized management model. Yet, such a management model requires librarians to constantly optimize the number of books, classification management and other aspects and sufficiently optimize the 
allocation of library resources, in order to meet the individual reading needs of university teachers and students at present.

\subsection{Professional Proficiency of Librarians Is Influenced}

In the information age, the information transmission of the library industry is fast and convenient, and librarians not only need to nimbly use information technology to carry out the work but also need to possess excellent professional proficiency and information capability. For example, a librarian should possess a repository of book-related knowledge and be able to write abstracts for books, to offer students conveniences when reading. Meanwhile, librarians should be able to distinguish between different categories of books and ensure the classification method is scientific and reasonable. But, this kind of work mode is a challenge to librarians. However, currently, teaching funds of universities are mostly used for enrollment and the improvement of school infrastructure, and have not placed emphasis on the enhancement of library management. This is the key problem that universities should pay attention to when optimizing library management in the new situation.

\subsection{Reform of the Management System}

At the present stage, in the teaching management mechanism, some universities have not updated library management regulations in accordance with the development needs of the new era in a timely manner, which results in the onesidedness of management and affects the quality and efficiency of management. For university libraries, to exercise standardized management over all the works, they must establish and perfect their supervisory and managerial mechanism, to regulate work behaviors of librarians and book borrowing behaviors of teachers and students.

\section{THE INNOVATION PATH OF UNIVERSITY LIBRARY MANAGEMENT IN THE INFORMATION AGE}

\subsection{An Intelligent Library Management System Should Be Established in University Libraries}

With the overall trend of the development of new technologies such as networkization, mobilization, intelligentization, blockchain and internet + intelligent push, university libraries should establish and perfect an intelligent management system, explore and analyze the reading needs of people by efficiently using cloud technology, clarify the direction of management, improve management measures in real time without being constrained by time and space, and further optimize management. For instance, if a reader does not remember the borrowing date and does not return the book on schedule, it will handicap library management. For this situation, it is necessary to amplify the application of data technology, ensure the scientificity and effectiveness of the application, and build a sound borrowing information management system. By applying this system, one can remind readers one day prior to the last day to return the book, which greatly lowers the probability of failing to return the book on time. [3]

For another example, Singapore has established a sound quality management system. Singaporean public libraries have set up an impeccable quality management system, and have been certified by the ISO9001 quality management system in 2002. The formulation of this system achieves the integration of the operating processes of a library and allows readers to experience standardized service. [4]

Singaporean public libraries independently developed the world's first electronic library management system in 2000, and applied RFID technology to the whole library system to automate and facilitate library management. [5] RFID is a system that uses radio frequency for version identification, tracking and management, and it is similar to bar code but it is better. Singaporean libraries can be returned books 24-hour, and successfully developed RFID-based library security door, RFID-based self-help book borrowing station, RFID-based sorting and stocktaking, and other automatic equipment.

At present, the library of University of Ji'nan also applies RFID technology to the whole library 
system, which offers great convenience to teachers and students that they can borrow and return a book fast without waiting in line, increases management efficiency, and reduces the operating costs of the library.

\subsection{University Libraries Should Establish the Concept of Informatization Management, and Establish and Improve the Management Mechanism}

In the information age, to change the service concept of traditional management, it is a necessity to get the management model of university libraries into the direction of informatization, popularize the advantage of the informatization management model to librarians on a regular basis, raise their awareness, completely change their management concept, make them aware of the advantage of the informatization management model, promote their changes in the way of thinking about work and manner of working, help them learn how to efficiently use data technology to carry out the work, and constantly meet diversified reading needs of teachers and students.

Next, an effective management mechanism should be established. Just like Chen Jin, curator of Shanghai Jiaotong University Library, pointed out in "The 12th Creative Forum for Library Management and Service": "Organization is a guarantee of the top management of library operation. A user-centered organizational reform is inevitable for the transformation and innovative development of libraries, and organizational reform should closely link up with the 'Double First-Class' Project and training strategy of the school. Department setting is a precondition for scientific management and the normal operation of libraries. In the process of transformation, it is necessary to reorganize old departments or set up new ones in due time, and create a management mechanism fit with the current environment."[6]

In the process of transformation, university libraries need to properly deal with department reorganization and team building, optimize the operating mechanism, enhance the improvement of the library management system, and continuously explore the new direction for library management.

\subsection{University Libraries Should Conduct Specialized Knowledge Training for University Librarians, and Improve Service Concept in the Information Age}

A universal problem among the work of university librarians is that they seldom communicate with teachers and students. For example, in some universities, "most teachers and students in Chinese universities focus on scientific research, but now some university librarians are not professional enough and their communication with students is ineffective."[7]

Therefore, it is necessary to conduct professional knowledge training for university librarians on a regular basis. Meanwhile, university librarians should constantly improve their professional skills, frequently communicate with teachers and students to satisfy their reading needs, and constantly enhance service quality. Furthermore, librarians should receive proper training in terms of service concept, service attitude, service specifications and other aspects.

\section{MEASURES TO DEVELOP THE SERVICE INNOVATION CAPABILITY OF UNIVERSITY LIBRARIANS IN THE INFORMATION AGE}

\subsection{Energetically Exploring Microservices and Establishing the New Concept of Big Data-based Library Service}

In "The 12th Creative Forum for Library Management and Service", the vice curator of Shanghai Normal University Library Cai Yingchun pointed out that "university library services concentrate on serving three aspects-teaching, research and policy-making consulting. Libraries should gradually involve from a 'resource center' which purely acquires literature into a 'resource learning center' which supports teaching and research, set up an embedded teaching resources and service module, offer teachers and students learning resources and learning support services, and reach the service purpose of fostering character and civic virtue while enriching campus culture."[8]

To achieve service innovation in these three aspects, university librarians must change the previous traditional service concept, establish consciousness of innovation, and set up 
characteristic services and optimize the mode of services, to let teachers and students who receive services feel satisfied and proud. In the context of digitalization, it is a must to energetically explore microservices, for example, Peking University Library uses WeChat Official Account to offer inquiry through ISBN barcode service; Southeast University Microservice Platform integrates a number of microservices including self-help explanation, reading pavilion service and microjournal full-text browse; the East China University of Science and Technology scans reader's ID card for verification for entry via WeChat and offer other new services. In short, it is necessary to make full use of the autonomous creativity of librarians when exploring innovative microservices, let them give full play to their role in innovative projects, and further drive the overall enhancement of value and status of the library.

Besides, against the background of informatization, big data, as a new technology for university libraries, helps drive the innovation of library services.

Library services follow the advent of big data. The short messaging service of mobile phones is made full use of to achieve multiple services, including notification of library lending, message notification of the arrival of new books, and reservation of a new book in advance, and to allow teachers and students to acquire the latest and timeliest service information. Meanwhile, WeChat, an application on the mobile phone, is a service channel that effectively narrows the distance between libraries and the great masses of teachers and students.

\subsection{Librarians Should Conduct Information Innovation of Personalized Services and Offer People-oriented Services}

Librarians can provide teachers and students with some of the most valuable and necessary information after sampling, analysis, integration and study of individual information. First, technical information of big data can be used to collect what teachers and students often index, their indexing habits and ways of browsing and data information. People may analyze with new science and technology to understand different needs of teachers and students, offer corresponding individualized services, completely change the traditional concept of passive service, walk out of libraries and go to school departments and research institutions to learn about relevant information, get to know the needs of research projects for library information resources in a timely manner, and establish a harmonious interaction. Meanwhile, to better offer people-oriented services, university libraries should organize relevant training for managers on a regular basis, arrange regular external training for librarians, and make managers master necessary services and information technologies, possess professional computer skills, and continue to improve their new media skills.

\subsection{Construction of Characteristic Library}

University libraries should increase input in the construction of libraries, increase digital resources of libraries, continue to improve the establishment of school literature archives, and enable teachers and students to make full use of these works of literature when doing researches. In modern society, "rare editions" and "collection editions" of lots of literature can only be found in university libraries. Digital documents can support the development of individualized library services, while developing library resources of new university libraries may meet the needs of teachers and students to consult and browse advanced reference documents and materials online, and help fully enjoy excellent cultural deposits of university libraries.[9]

In addition, it is necessary to reinforce the building of characteristic databases, complete related implementation and constant update, and make sure the construction of libraries is improved on all fronts.

Characteristic database mainly enters all kinds of complete data to use these data to verify teachers, students and visitors, and complete data entry of library books. A characteristic database can effectively offer teachers and students convenient and quick services.[10]

Characteristic database, on the one hand, reaches the purpose of data sharing, further improves information resources, and offers help to many teachers and students; on the other hand, it facilitates their consultation, shares data in the library, further strengthens the scientific connections between different data, and significantly enhances data quality. 


\subsection{Makerspace Can Achieve Constant Innovation in the Service Mode of University Libraries}

Makerspace can meet the diverse information needs of teachers and students, and offer creative products needed by them. Libraries should establish corresponding service facilities and service means, and offer targeted services. Meanwhile, it achieves the spatial supply of knowledge and information to meet the needs of teachers and students, provide maker teams with a space to achieve creative products, and promote innovative development of library services.

The overall future direction of libraries is changing from the current knowledge factory and innovation catalyst to a future smart library, and the new mission of university libraries is to use highquality resources and active services to get involved in multiple aspects including teaching, scientific research, innovation, management and culture, thus supporting personnel training of the schools and the "Double First-Class" Project.

University libraries should continue to improve the management system of the library, constantly transform and innovate library service modes and forms of activity, conduct characteristic reading promotion activities and services to keep abreast of the times, and endeavor to enhance comprehensive quality and professional skills of librarians. Moreover, university libraries should develop "people-oriented" new library services, meet the diverse and individual needs of the great masses of teachers and students, and open a new chapter in library management and service.

\section{CONCLUSION}

University library is the core department of university information, which directly reflects the image of the university and plays an important role in the construction of university. In the information age, the management of university library is facing various challenges. It is necessary to further strengthen the information construction and promote the personalized development.

\section{AUTHORS' CONTRIBUTIONS}

This paper is independently completed by Hui Wang.

\section{REFERENCES}

[1] IFLA. Development and access to information 2019[EB/OL]. https://da2i.ifla.org/da2i-re-port-2019.

[2] Chu Jingli \& Zhao Yan. The Transformation of the Library from Resource Capability to Service Capability [J]. Library and Information Service, 2019, 63 (1): 11-17.

[3] Zhang Guoyou. Application of Big Data in Library Management and Service [J]. Comparative Study of Cultural Innovation, March 2020, Issue 9.

[4] Ren Lei. A Study of the Operating and Management System of Singaporean Libraries [J]. Media Forum, Volume 3 Issue 05, May 2020.

[5] Deng Bin. View on the Role Transformation of the Librarians Based on the Development of Singapore Library [J]. Journal of Nanjing Vocational University of Industry Technology, 2008, 8 (4): 81-85.

[6] Yin Huanhuan, Li Yaping, Zhang Lulu, \& Gu Yeqing. An Overview of the 12th Creative Forum for Library Management and Service [J]. Journal of Academic Libraries, February 2020, Issue 2, pp.22.

[7] Wang Danni. A Survey and Study of the Quality of the Librarians in Anhui Agricultural University [D]. Anhui University: 2017.

[8] Yin Huanhuan, Li Yaping, Zhang Lulu, \& Gu Yeqing. An Overview of the 12th Creative Forum for Library Management and Service [J]. Journal of Academic Libraries, February 2020, Issue 2, pp. 23.

[9] Pang Yange. Construction Scheme and Technical Research of Digital Campus [D]. Tiangong University: 2017.

[10] Cui Xiaoxi \& Wen Mingming. Personalized Information Service Countermeasures for University Libraries in the Context of Big Data [J]. China New Telecommunications, 2020 Issue 15. 